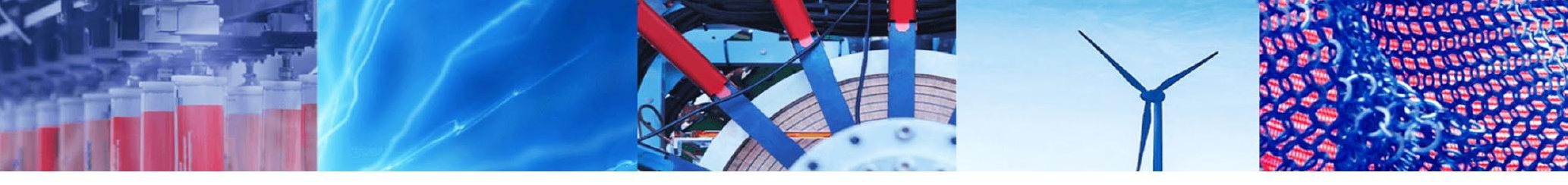

Research Article

\title{
A simple procedure to obtain nanodiamonds from leftover of HFCVD system for biological application
}

\author{
Carolina Ramos Hurtado ${ }^{1,2} \circledast$. Cristiane da Costa Wachesk ${ }^{1,3} \cdot$ Rafaela Campos Queiroz $^{1,2}$. \\ Erenilda Ferreira de Macedo ${ }^{1} \cdot$ Rebeca Falcão Borja de Oliveira Correia ${ }^{3} \cdot$ Thalita Sani Taiariol $^{3} \cdot$ Milton Faria Diniz $^{4}$. \\ Alexandre Martins Isaias dos Santos ${ }^{1}$. Thais Larissa do Amaral Montanheiro ${ }^{5}$. Gabriela Ramos Hurtado ${ }^{6}$ \\ Vladimir Jesus Trava-Airoldi ${ }^{3}$. Dayane Batista Tada ${ }^{1}$ (1)
}

Received: 6 July 2019 / Accepted: 6 January 2020 / Published online: 6 February 2020

(c) Springer Nature Switzerland AG 2020

\begin{abstract}
Nanodiamonds (NDs) are amongst the most investigated carbon-based nanostructures due to their chemical stability and favorable mechanical properties. Despite the number of works on methods for NDs production, one of the main challenges is to achieve their colloidal stability in aqueous suspension. Additionally, NDs are normally obtained by expensive, complex and time-consuming process. Herein, it was presented a facile method to obtain NDs in aqueous suspension by using columnar structure diamond from Hot-Filament Chemical Vapour Deposition reactor (HFCVD). CVD diamond leftover thick film from CVDVale Company was used. Therefore, this method has the advantage of being not only practical but also cost-effective since it brings a profitable use of CVD diamond leftover. The Diamond thick film was submitted to ultrasonic cavitation in the presence and absence of $\mathrm{ZrO}_{2}$ microbeads in aqueous medium. The NDs hydrodynamic diameter and the stability in aqueous suspension were monitored by light scattering, size and morphology were analyzed by transmission electronic microscopy. Considering the wide application of NDs in biomedical devices, cytotoxicity of aqueous suspensions of NDs was evaluated against murine embryonic fibroblast cells. Furthermore, NDs were functionalized with hydrogen and carboxyl groups. NDs aqueous suspension of straight size distribution was obtained even in the absence of $\mathrm{ZrO}_{2}$ beads, indicating that they may be dispensable in order to decrease NDs size. NDs of average hydrodynamic diameter of $22 \mathrm{~nm}$ and $-35 \mathrm{mV}$ of Zeta-potential were obtained after ultrasonic cavitation followed by $2 \mathrm{~h}$ of centrifugation, not demonstrating cytotoxicity to cells at very low $(0.05-0.5 \mu \mathrm{g} / \mathrm{mL})$ nor at higher concentrations $(116 \mu \mathrm{g} / \mathrm{mL})$. Nevertheless, NDs showed a moderate cytotoxicity at intermediary concentration range $(0.5-2.2 \mu \mathrm{g} / \mathrm{mL})$. From our knowledge, this is the first work that reports on a facile method for providing NDs aqueous suspension with high colloidal stability from HFCVD diamond leftover.
\end{abstract}

Keywords Nanodiamonds - Ultrasonic cavitation · CVD diamond · Functionalization · Cytotoxicity · Colloidal suspension

$\triangle$ Carolina Ramos Hurtado, carolina.hurtado@ifsp.edu.br; Dayane Batista Tada, d.tada@unifesp.br| ${ }^{1}$ Nanomaterials and Nanotoxicology Laboratory, Institute of Science and Technology, Federal University of São Paulo (UNIFESP), Talim, 330 - Vila Nair, São José dos Campos, São Paulo 12231-280, Brazil. ${ }^{2}$ Federal Institute of São Paulo (IFSP), Rod. Pres. Dutra, km 145 - Jardim Diamante, São José dos Campos, São Paulo 12223-201, Brazil. 'Sensors and Materials Associated Laboratory, National Institute for Space Research (INPE), Av. dos Astronautas, 1.758 - Jardim da Granja, São José dos Campos, São Paulo 12227-010, Brazil. ${ }^{4}$ Aerospace Science and Technology Department, Institute of Aeronautics and Space (IAE), Praça Marechal Eduardo Gomes, 50 - Vila das Acácias, São José dos Campos, São Paulo 12228-900, Brazil. ${ }^{5}$ Fundamental Sciences Division, Technological Institute of Aerocautics (ITA), Praça Marechal Eduardo Gomes, 50 - Vila das Acácias, São José dos Campos, São Paulo 12228-900, Brazil. ${ }^{6}$ Institute of Science and Technology, São Paulo State University (UNESP), Rod. Pres. Dutra, Km 137,8 - Eugênio de Melo, São José dos Campos, São Paulo 12247-004, Brazil. 


\section{Introduction}

Carbon-based nanomaterials are extremely interesting for biomedical applications since carbon is the main constituent of living organisms. Fullerenes, carbon nanotubes, graphene and nanodiamonds (NDs) are among the most investigated carbon-based nanomaterials. More specifically, the NDs, have outstanding mechanical properties, low toxicity, high biocompatibility [59] and high stability due to chemical inertia of the diamond core $[47,59]$. When Nitrogen Vacancy centers are present in the diamond crystalline lattice, they become fluorescent and useful in optical, sensorial and bioimaging applications and also as quantum sensors because fluorescence is sensitive to environmental parameters such as temperature, electric and magnetic fields $[2-4,23,28]$.

NDs applications can be further extended by surface functionalization with a diverse type of chemical groups, modulating NDs hydrophobicity and (bio)molecular affinity. Recently, studies showed that the NDs bactericidal activity against the $E$. coli bacteria was afforded by oxidized and partially oxidized surface groups by promoting interactions with the cellular components, whereas the anisotropic distribution of the charges on the surface of the NDs, facilitates changes on the cell membrane of gram negative bacteria [51]. Although there is little information regarding the NDs cytotoxicity there is some evidences that NDs are not toxic to eukaryotic cells $[26,29,37,55]$, which has encouraged several works towards the use of NDs as drug delivery platforms $[11,15,39,45,58]$.

Diamonds and NDs have been synthesized by different techniques, for example: high pressures high temperatures (HPHT) [27], plasma-enhanced chemical vapor deposition (PECVD), hot filament chemical vapor deposition (HFCVD), etc., and explosive detonation [27], laser ablation [3, 12,56], chlorination of carbides [52], ultrasonic cavitation $[9,16]$, etc.... respectively.

The stability of NDs is compromised by their small size $(\sim 5 \mathrm{~nm})$ and surface chemistry [33]. The presence of oxidized groups on the surface of NDs induces the aggregation by hydrogen bonds and NDs aggregates of 100 to $200 \mathrm{~nm}$ are commonly observed [21,22]. Therefore, methodologies for NDs disaggregation and stabilization of NDs in suspension have attracted much effort of researchers. However, the establishment of a cost-effective method is still challenging since most part of the methods requires expensive equipment, and reactants.

One of the most used techniques for improving NDs stability in suspension is the Bead-Assisted Sonic Disintegration (BASD) $[5,7,20,24,34]$. In this technique, dense $\mathrm{ZrO}_{2}$ microbeads of $30 \mu \mathrm{m}$ are used in order to break NDs aggregates by collision driven by the energy of ultrasonic [24]. However, the use of these microbeads brings the disadvantage of contamination with $\mathrm{ZrO}_{2}$ residues, requiring additional purification steps with acids or bases. In addition to the time-consuming, these steps may compromise the safety and costs in the production of NDs [7, 30, 31, 49].

Alternative techniques for NDs disaggregation include Salt Assisted Ultrasonic Disaggregation (SAUD) [32, 36, 46], which uses salts such as $\mathrm{NaCl}, \mathrm{KCl}$, sodium acetate, among others. In this case, the stability of NDs in suspension is enhanced by the interaction of the cationic ions with the negative groups, such as carboxyl on the surface of the oxidized NDs. Another alternative for the NDs disaggregation is the surface hydrogenation of NDs [53]. The monofunctionalization of the NDs surface decreases the interaction between particles and prevents NDs aggregation $[19,41]$.

In the present study, NDs in suspension were prepared from microcrystalline diamonds obtained on an industrial scale by Hot-Filament Chemical Vapor Deposition (HFCVD). Commonly, CVD diamond coating is used to improve mechanical properties and biocompatibility of biomedical devices. Notably, inside HFCVD reactors not only the surface of specific substrate is covered by CVD diamond, but a lot of "holders" is coated and, so used for. Therefore, there is a considerable amount of CVD diamond leftover produced during the HFCVD coating process. In this way, the aim of this work was to give a profitable use of this CVD diamond leftover by using it to produce NDs in aqueous suspension. The diamond was submitted to ultrasonic cavitation in the presence and absence of $\mathrm{ZrO}_{2}$ microbeads in aqueous medium. The influence of $\mathrm{ZrO}_{2}$ in this process was evaluated regarding NDs hydrodynamic diameter and stability in suspension, monitored by dynamic light scattering. Size and morphology of NDs were analyzed by transmission electronic microscopy (TEM). Furthermore, aiming at the biological applications of NDs, cytotoxicity of aqueous suspensions of NDs of 20 to $90 \mathrm{~nm}$ was evaluated against murine embryonic fibroblast (MEF) cells. Finally, the produced NDs were functionalized with hydrogen and carboxyl groups, which provides a wide range of possible applications of these NDs from nano-sized fillers in materials field to drug delivery platforms by covalent linking of bioactive molecules.

\section{Experimental details}

\subsection{Materials}

In this study, synthetic diamond in the form of self-contained films produced by Hot-Filament Chemical Vapor 
Deposition (HFCVD) supplied by CVDvale and National Institute for Space Research (INPE) was used to obtain aqueous suspensions of NDs. Deionized water (type 1) was obtained from Deionizer Millipore Milli-Q system. Dulbecco's

Modified Eagle's Medium (DMEM) (Gibco) was prepared in deionized water and buffered with sodium bicarbonate (Synth, Brazil) and supplemented with fetal bovine serum (FBS) (Vitrocell Embriolife). Streptomycin, ampicillin, 3-(4,5dimethylthiazol-2-yl)-2,5-diphenyltetrazolium bromide (MTT), and dimethylsulphoxide (DMSO) were purchased from Sigma-Aldrich. Sulfuric, nitric, hydrochloric and hydrofluoric acids were purchased from Synth (Brazil). Acrylic acid with purity greater than $99.5 \%$ was received from BASF (The Chemical Company, Brazil).

\subsection{Microcrystalline diamonds}

The 20 to $50 \mu \mathrm{m}$ microcrystalline diamond was grown in columnar structure without re-nucleation in a HFCVD ( Hot Filament Chemical Vapor Deposition) reactor. A set of five $125 \mu \mathrm{m}$ tungsten filaments, kept at a temperature around $2200{ }^{\circ} \mathrm{C}$ and positioned at $5 \mathrm{~mm}$ above the substrates was the activation region. The total gas pressure was of 50 Torr during the $3 \mathrm{~h}$ of growth. The reactive gas mixture consisted of $2 \% \mathrm{CH}_{4}$ and $98 \% \mathrm{H}_{2}$. The ramp downturn off period was of $1 \mathrm{~h}$. Under these CVD conditions, the deposition rate, at $700{ }^{\circ} \mathrm{C}$, was approximately $0.43 \mu \mathrm{m} / \mathrm{h}$. This is a roughly used process in CVDVale that is a company specialized on the CVD coating. Normally, during the coating process. Therefore, by using small samples of substrate, the CVD diamond leftover could be recovered, and it was used herein in order to produce NDs in aqueous suspension.

\subsection{NDs in aqueous suspension}

The methodology developed herein was based on the ultrasonic cavitation, which is a method of propagation of ultrasonic waves in the liquid phase, resulting in alternating cycles of low and high pressure, creating vacuum bubbles that implode producing high speed liquid jets, which provide the material disaggregation. All the experimental steps are depicted in the flow chart below (Scheme 1).

Firstly, the CVD diamond thick film was macerated in agate mortar and pestle and then sieved in 200 mesh sieve.

Dispersing of the diamond powder $(250 \mathrm{mg})$ was carried in $\mathrm{H}_{2} \mathrm{O}(50 \mathrm{~mL})$ (type 1 ; resistivity of $>18.2{\mathrm{M} \Omega \mathrm{cm}^{-1}}^{-1}$ ). This dispersion was submitted to ultrasonic cavitation at a power of $450 \mathrm{~W}$ for $30 \mathrm{~min}$ (Sonics VibraCell). Afterward, an aliquot of the suspension has been removed and named ND- $\mathrm{h}$ and other aliquot was centrifuged in Hettich Rotina

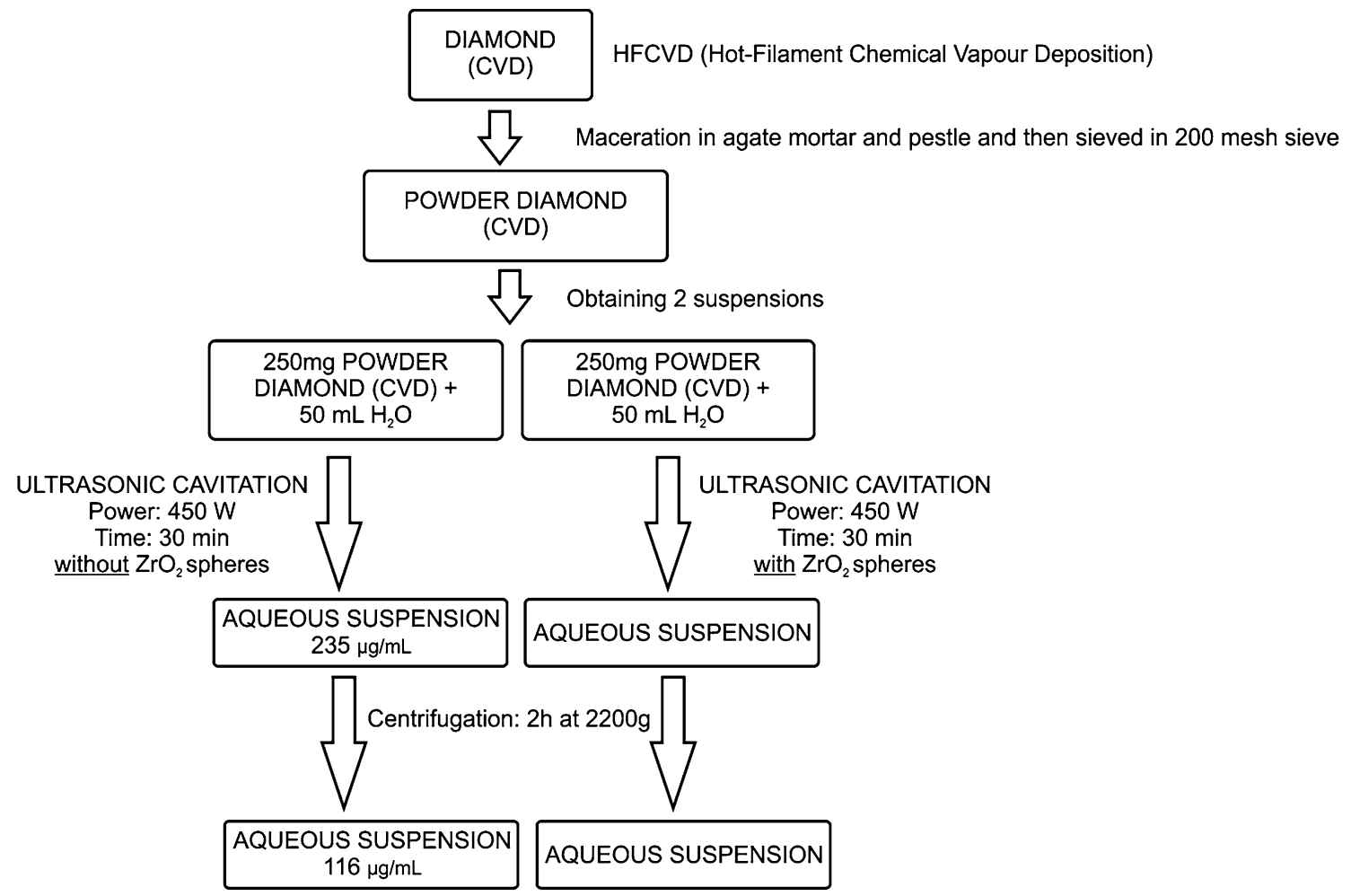

Scheme 1 Schematic representation of the experimental steps for obtaining aqueous suspension of NDs 
$420 \mathrm{R}$, for $2 \mathrm{~h}$ at $2200 \mathrm{G}$ to remove remaining aggregates. The final suspension was named ND- $2 \mathrm{~h}$. The resulting dispersions contained about 200 and $100 \mu \mathrm{g} / \mathrm{mL}$ of NDs respectively.

To measure the concentrations of each NDs suspension, aliquots of $2 \mathrm{~mL}$ of each suspension were lyophilized in triplicate. After lyophilization, the recovered NDs were weighed and the concentration of each aqueous NDs suspensions was calculated by using the value of initial volume.

The $\mathrm{pH}$ of the ND- $\mathrm{h}$ and ND- $2 \mathrm{~h}$ aqueous suspensions were determined at $25^{\circ} \mathrm{C}$ using a pHmeter MS Tecnopon $\mathrm{mPA}-210$. The values were of 8.00 and 8.17 of ND- $\mathrm{h}$ and ND-2 $h$, respectively.

\subsection{NDs characterization}

\subsubsection{Size and zeta potential: DLS (dynamic light scattering)}

The zeta potential, hydrodynamic diameter and particle size distribution of the NDs samples were analyzed by dynamic light scattering in a Beckman-Coulter Delsa Nano C zeta-sizer analyzer (Beckman Coulter Inc., Brea, CA, USA).

\subsubsection{Particle morphology: TEM (transmission electron microscopy)}

The size and morphology of NDs were analyzed by transmission electron microscopy (TEM). Images of the NDs were obtained using a $120 \mathrm{kV} \mathrm{FEI} \mathrm{Tecnai.} \mathrm{The} \mathrm{NDs} \mathrm{samples}$ were prepared in ultrathin 200 mesh carbon-coated copper grids-CF200-Cu (EMS).

\subsubsection{FT-IR (Fourier transformed infrared spectroscopy)}

The infrared spectra were acquired by Fourier transform infrared spectroscopy using a universal attenuated total reflectance sensor (FT-IR-UATR) (Perkim Elmer Spectrum, model Frontier). The FT-IR spectrum was an average of 32 scans at a speed of $2 \mathrm{~s}$ per scan in a range of $400-4000 \mathrm{~cm}^{-1}$. The resolution of the spectrometer was of $4 \mathrm{~cm}^{-1}$.

\subsubsection{Raman spectroscopy}

Raman spectra of the materials were collected with a LabRAM HR Evolution model Raman Spectrophotometer (Horiba) using an Ar laser ( $514 \mathrm{~nm}$ ). The spectra were measured in the range of 400 to $4000 \mathrm{~cm}^{-1}$ with acquisition time of $20 \mathrm{~s}$.

\subsubsection{X-ray diffraction (XRD)}

Crystalline structure and the presence of impurity were investigated by X-ray diffraction (XRD), using a PANalytical (X'Pert PRO), operating at $45 \mathrm{kV}$ and $40 \mathrm{~mA}$. XRD patterns were collected in the $2 \theta$ range from 20 to $95^{\circ}$ at step size of $0.02^{\circ}$.

\subsubsection{X-ray photoelectron spectroscopy (XPS)}

XPS measurements were carried out on Kratos Axis Ultra DLD using a monochromated Al Ka X-ray source of $1486.6 \mathrm{eV}$ at a power of $120 \mathrm{~W}$. The survey XPS spectra were acquired with pass energy (PE) of $160 \mathrm{eV}$. The high resolution $01 \mathrm{~s}$ and $\mathrm{C} 1 \mathrm{~s}$ XPS spectra were acquired with energy passage of $40 \mathrm{eV}$. The spectra were corrected to the carbon spectrum set at $284.8 \mathrm{eV}$. The peak fitting was performed using CasaXPS software and least-square fitting procedure was applied.

\subsubsection{Cell viability assay}

Murine Embryonic Fibroblast cells (MEF) were thawed and cultured in plastic bottles with vented cover of $75 \mathrm{~cm}^{2}$ (Sarstedt), containing Dulbecco's Modified Eagle's Medium (DMEM) supplemented with $10 \%$ (v/v) FBS, sodium bicarbonate $(2 \mathrm{~g} / \mathrm{L})$, streptomycin $(0.1 \mathrm{~g} / \mathrm{L})$, and ampicillin $(0.025 \mathrm{~g} / \mathrm{L})$. Cells were incubated at $37^{\circ} \mathrm{C}$ in a humidified atmosphere with $5 \% \mathrm{CO}_{2}$. After reaching confluence, the cells were analyzed to evaluate the viability by exclusion of Trypan blue method. The viable cells were counted in a Neubauer chamber.

Cell proliferation and viability was determined by the colorimetric method of reduction of 3-(4,5dimethylthiazol2-yl)-2,5 diphenyl tetrazolium bromide (MTT). Cells incubated in the absence of samples were considered as $100 \%$ of viability. Cell proliferation was evaluated after $24 \mathrm{~h}$ of incubation of cells in the presence of NDs at different concentration ranges. In the assays with NDs obtained without $\mathrm{ZrO}_{2}$ beads and without centrifugation (ND/0 h), NDs were at $0.05 \mu \mathrm{g} / \mathrm{mL}-3.00 \mu \mathrm{g} / \mathrm{mL}$. NDs aqueous suspensions obtained without beads $\mathrm{ZrO}_{2}$ and after $2 \mathrm{~h}$ of centrifugation (NDs/2 h) were at the concentration of $0.01-116 \mu \mathrm{g} / \mathrm{mL}$. The cells were seeded into 96 well plates (DNase and RNase free -Nest Biotechnology Co. Ltd) at a density of $10^{4}$ cells/well. The effect of centrifugation was also evaluated by incubating cells for samples $24 \mathrm{~h} \mathrm{ND} / 0 \mathrm{~h}$ and ND/2 h. After incubation, the medium was removed and the cells were washed with fresh PBS. Then, the cells were incubated for $3 \mathrm{~h}$ with $100 \mu \mathrm{L}$ of an MTT solution $(0.50 \mathrm{mg} / \mathrm{mL})$. After washing the cells with fresh PBS, dimethylsulphoxide (DMSO) was used to solubilize the formazan crystals. The final absorbance of formazan was 
measured in a microplate reader (BioTek) at $540 \mathrm{~nm}$. The absorbance of cells in absence of samples was considered as $100 \%$ of viability. The cell viability data were analyzed by 1 -way ANOVA and Tukey's multiple range $(P<0.05)$ to determine statistical differences between different groups of samples.

\subsection{NDs powder purification}

The aqueous suspension obtained after the cavitational process, was was dried by lyophilization. The obtained ND powder was treated in 3 stages:-Aqua Regia Solution $\left(\mathrm{HNO}_{3}: \mathrm{HCl}=1: 3\right)$ for the removal of impurities contained in the reactor;-Piranha Solution $\left(\mathrm{H}_{2} \mathrm{SO}_{4}: \mathrm{H}_{2} \mathrm{O}_{2}=4: 1\right)$ for the removal of organic contaminants and hydrofluoric acid (HF) for the removal of $\mathrm{SiO}_{2}$ from contamination of the sample by abrasion of the Agate mortar.

\subsection{NDs surface functionalization}

NDs surface was firstly monofunctionalized by surface hydrogenation (ND-H), followed by photofunctionalization with carboxylic groups (ND-COOH).

\subsubsection{Hydrogenation (ND-H)}

The purified ND powder was subjected to an $\mathrm{H}_{2}$ Plasma Enhanced Chemical Vapor Deposition process (PECVD). A sample of ND of $15 \mathrm{mg}$ was deposited in a sample holder and placed in a reactor. Then the reactor was purged with argon (Ar) at a pressure of 2.4 mtorr, with a voltage of $-600 \mathrm{mV}$, for two minutes $(3.5 \mathrm{sccm})$. Following, hydrogen gas $(10 \mathrm{sccm})$ and argon $(3.5 \mathrm{sccm})$ were inserted under a

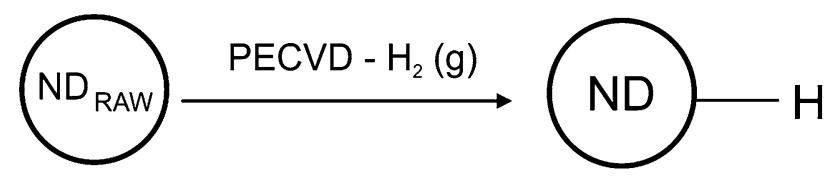

Scheme 2 Schematic representation of the nanodiamonds hydrogenation pressure of $4.1 \mathrm{mtorr}$ at a voltage of $-800 \mathrm{mV}$, for $5 \mathrm{~min}$ (Scheme 2). This procedure was repeated, with an interval for manual homogenization of the powder inside the holder in order to enhance the homogeneity of surface hydrogenation.

\subsubsection{Carboxylation (ND-COOH)}

The hydrogenated sample was subjected to a process of photofunctionalization with acrylic acid by following a protocol proposed by Wang et al. [50] but with some modifications. Briefly, acrylic acid glacial (BASF-The Chemical Company, $>99.5 \%$ ) was added dropwise on a sample of $\mathrm{ND}-\mathrm{H}$ until all the powder was covered. Then, the system was placed in a U.V. chamber with a $254 \mathrm{~nm}$ lamp for a period of $72 \mathrm{~h}$ (Scheme 3). After this time, the excess of acid was neutralized by washing the powder several times with water, followed by centrifugation $(2200 \mathrm{G}, 10 \mathrm{~min}$ and $25^{\circ} \mathrm{C}$ ). This process was repeated until the wash water was at neutral pH. Finally, the powder was air-dried at room temperature.

\section{Results and discussion}

\subsection{NDs size and polydispersity}

The influence of $\mathrm{ZrO}_{2}$ in the process of cavitation was evaluated regarding NDs size and polydispersity of the aqueous suspension. The values of hydrodynamic diameter obtained by DLS are depicted in Table 1. The average hydrodynamic diameter of NDs prepared in the absence of $\mathrm{ZrO}_{2}(\mathrm{D}=77 \pm 21 \mathrm{~nm})$ was very similar to the hydrodynamic diameter of NDs prepared with $\mathrm{ZrO}_{2}(83 \pm 21 \mathrm{~nm})$ suggesting that $\mathrm{ZrO}_{2}$ beads did not enhance particles disagglomeration in the samples used herein. Similarly, $\mathrm{ZrO}_{2}$ beads did not change the NDs polydispersity since the full width at half maximum (FWHM) of the size distribution curves (Fig. 1) was the same for NDs suspension obtained with and without $\mathrm{ZrO}_{2}$. Aiming the smallest size of NDs, the main parameter to be settled is the centrifugation time

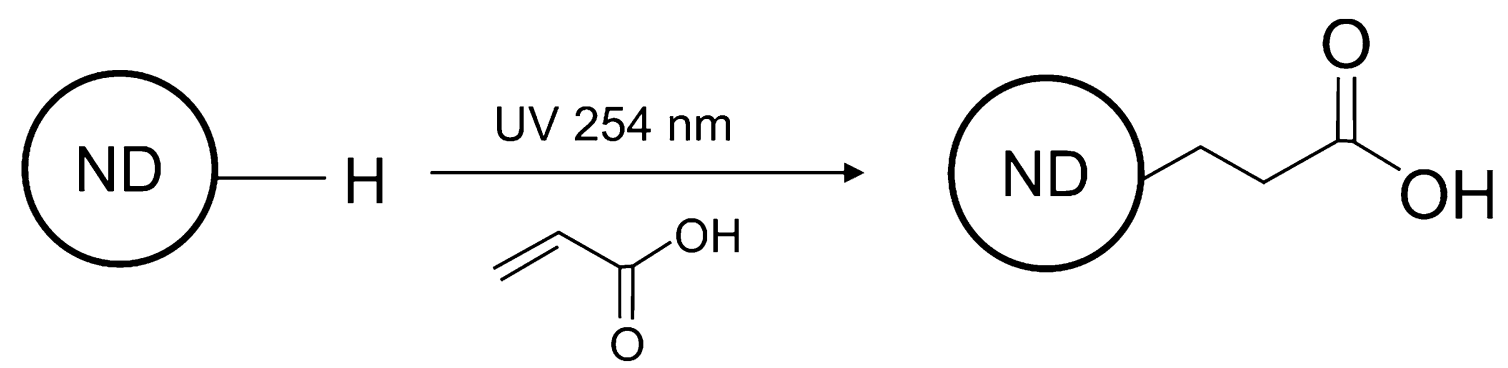

Scheme 3 Schematic representation of the nanodiamonds carboxylation 
Table 1 Hydrodynamic diameter, FWHM and Zeta Potential of the NDs samples

\begin{tabular}{lllrll}
\hline & $\begin{array}{l}\text { Centrifugation } \\
\text { time (hours) }\end{array}$ & $\begin{array}{l}\text { Hydrody- } \\
\text { namic diameter } \\
(\mathrm{nm})\end{array}$ & FWHM & $\begin{array}{l}\text { Concentration } \\
(\mu \mathrm{g} / \mathrm{mL})\end{array}$ & $\begin{array}{l}\text { Zeta } \\
\text { potential } \\
(\mathrm{mV})\end{array}$ \\
\hline With $\mathrm{ZrO}_{2}$ spheres & 0 & 83 & 42 & - & - \\
$\left(\mathrm{ND}_{\text {withZrO2 }}\right)$ & 2 & 22 & 7 & - & - \\
Without $\mathrm{ZrO}_{2}$ spheres & 0 & 77 & 42 & 235 & -36 \\
$(\mathrm{ND})$ & 2 & 20 & 7 & 116 & -35 \\
\hline
\end{tabular}

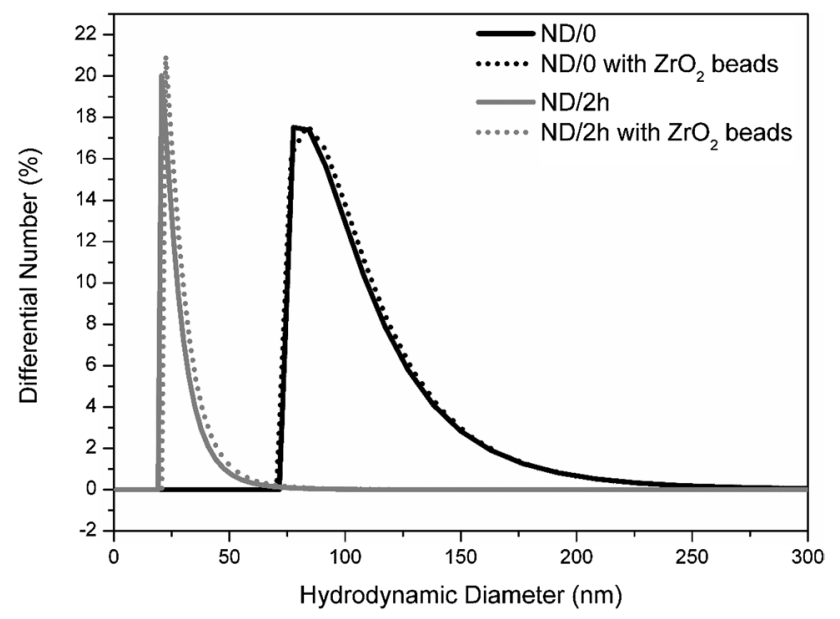

Fig. 1 DLS size distribution curves of NDs in suspension obtained after ultrasonic cavitation in the presence and absence of $\mathrm{ZrO}_{2}$ beads followed by $2 \mathrm{~h}$ of centrifugation (ND/2 h) or without centrifugation (ND/O h)

of the suspension. As can be seen in Table 1, the centrifugation of $2 \mathrm{~h}\left(2200 \mathrm{G} ; 25^{\circ} \mathrm{C}\right)$, provided the precipitation of bigger particles and the average diameter of NDs in suspension reduced from 83 to $22 \mathrm{~nm}$ in the NDs suspension obtained without $\mathrm{ZrO}_{2}$ and from 77 to $20 \mathrm{~nm}$ in the NDs suspension obtained with $\mathrm{ZrO}_{2}$ beads. Centrifugation also improved polydispersity of the suspension since the FWHM reduced from 42 to 7 in both kinds of suspension, reflecting the narrowing of the size distribution curves (Fig. 1). Although centrifugation has been shown as an important step to improve the quality of NDs suspension, it is noteworthy that this step compromises the yield of the process since the concentration was very low $(116 \mu \mathrm{g} / \mathrm{mL})$.

NDs size and morphology were analyzed by TEM. The images (Fig. 2) showed spherical particles both in the samples obtained with or without $\mathrm{ZrO}_{2}$ beads. NDs obtained without $\mathrm{ZrO}_{2}$ seemed to be better dispersed than NDs obtained with $\mathrm{ZrO}_{2}$. In this case, the observation of individual particles was hampered by the presence of bigger agglomerates. Even so, the size of individual particles was measured by using the image J software and the size distribution curves were obtained by a Gaussian fit (Fig. 2). The average diameter was similar to both types of NDs and therefore, as also observed in the hydrodynamic diameter, $\mathrm{ZrO}_{2}$ beads did not change the size of NDs particles obtained from CVD-diamond.

The improvement in the polydispersity by centrifugation due to the removal of agglomerates was confirmed by the TEM image of NDs after $2 \mathrm{~h}$ of centrifugation (Fig. 3 ). NDs were spherical and a narrow size distribution curve indicated NDs of $(14 \pm 1) \mathrm{nm}$ of average diameter.

One of the most challenging feature of the obtaining process of NDs is to achieve their colloidal stability. Although NDs of small diameters have been obtained by the most diverse techniques, they were prone to form big aggregates in solution unless some kind of coating or functionalization were used. Despite the fact that NDs size is normally measured only by electronic microscopy $[8,35,48,51]$ it is possible to claim that the NDs obtained here presented very similar size then the NDs reported by other researchers. By using microwave plasma-assisted chemical deposition, Vandenbulcke et al. [48] obtained NDs of 10-100 nm although some particles of 2-10 nm were also observed. In the work of Park et al. [35], very small NDs of 4-6 nm were observed by TEM however the stability of these NDs in suspension was not evaluated. According to Eldawud et al. [8], NDs of 3-7 nm were able to form aggregates of $30-100 \mathrm{~nm}$ resulting in a mean hydrodynamic diameter of $63.6 \mathrm{~nm}$ in aqueous suspension. Wehling et al. [51] obtained NDs in aqueous suspension with very similar hydrodynamic diameter $(60 \mathrm{~nm})$ by submitting commercially available NDs to oxygenation methods and different conditions of annealing. Even if the hydrodynamic diameter of the NDs obtained herein in aqueous suspension was close to the values reported by them (83-77 $\mathrm{nm})$, a suspension of smaller NDs were obtained after centrifugation. The colloidal stability of smaller NDs could be result of the increased Zeta-potential of these NDs. The Zeta-potential of the NDs after centrifugation was of $-35 \mathrm{mV}$ whereas NDs obtained by Eldawud et al. [8] presented Zeta-potential of $-28 \mathrm{mV}$. Despite the similarity regarding size and Zeta-potential, the mentioned works reported on more complex methodologies which required not only more expensive equipment and chemical reactants but were also time-consuming. In addition 
Fig. 2 TEM images and histograms of size of NDs cavitation without centrifugation process. a NDs grains obtained without $\mathrm{ZrO}_{2}$ beads, b NDs grains obtained with $\mathrm{ZrO}_{2}$ beads grains obtained by ultrasonic

a
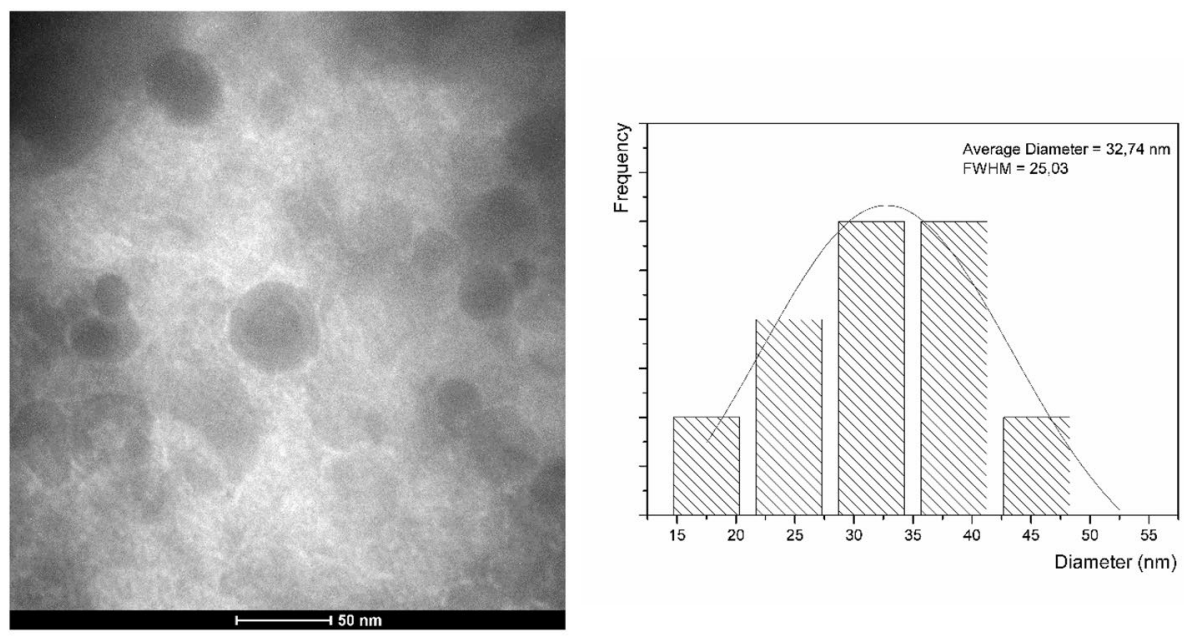

b
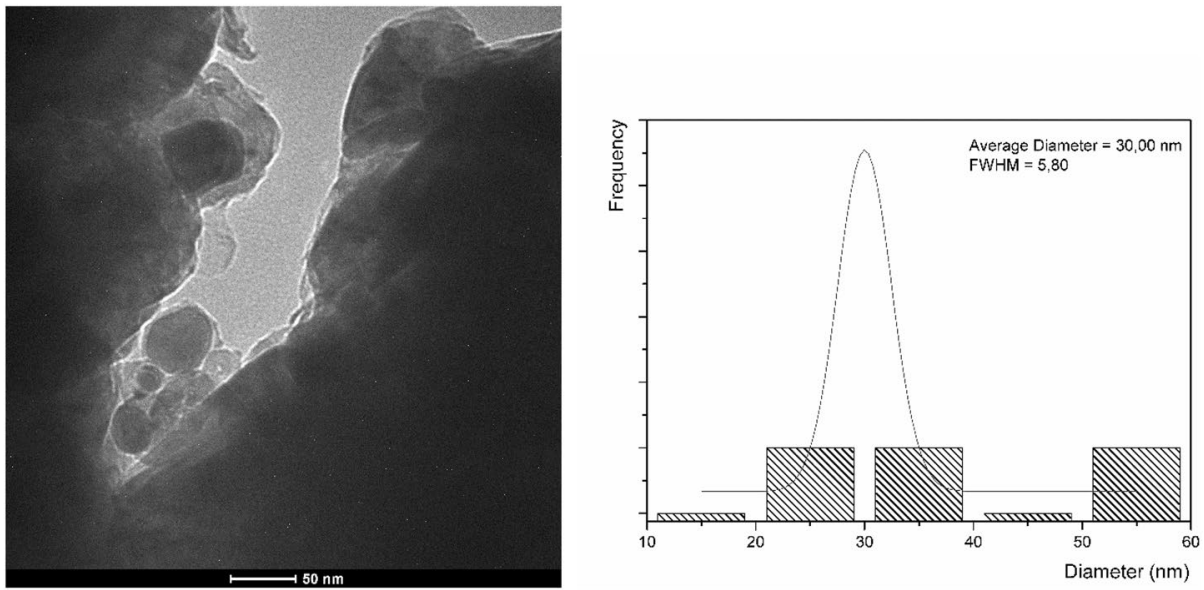

Fig. 3 TEM images and histograms of NDs obtained by ultrasonic cavitation without $\mathrm{ZrO}_{2}$ beads with centrifugation for $2 \mathrm{~h}$ at $2200 \mathrm{G}$ at various magnifications showing
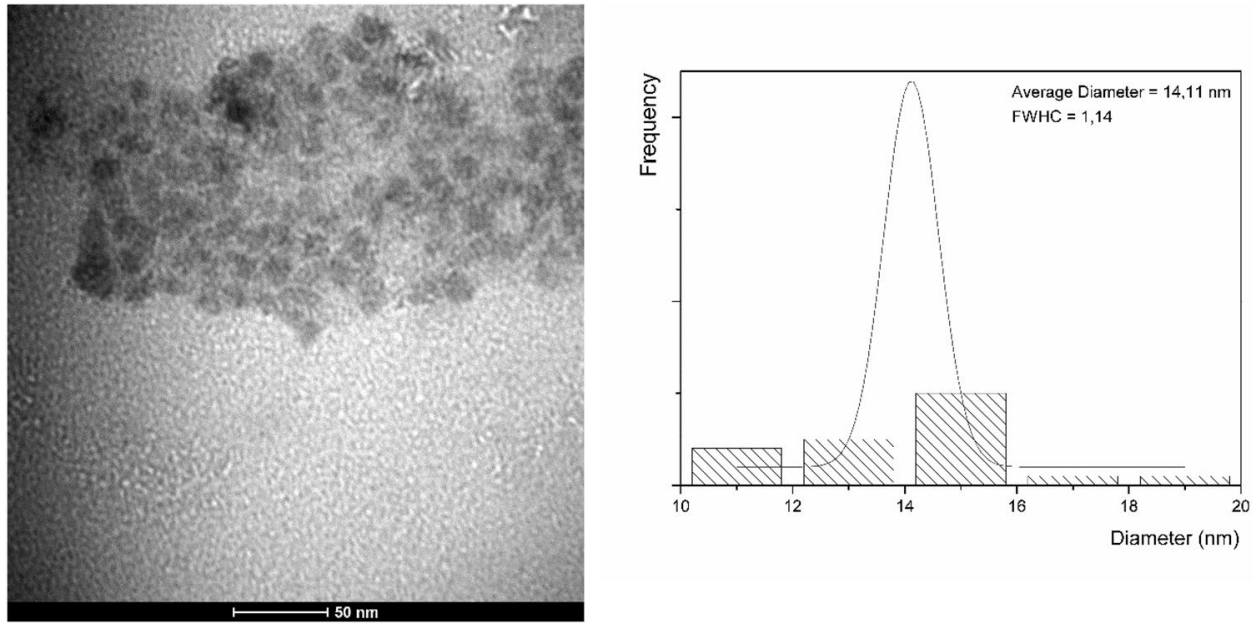

to the easiness of the procedure described here it has to be highlighted that it is a low-cost method to obtain NDs stable in aqueous suspension with small size and straight size distribution.

Since the use of $\mathrm{ZrO}_{2}$ beads in the cavitation process had shown to be worthless to improve NDs suspension and we aimed at the simplest method for NDs preparation, the following characterization was performed only with NDs obtained without $\mathrm{ZrO}_{2}$ beads. 


\subsection{Diamond identification}

The presence of diamond in the samples was confirmed by the Raman analysis (Fig. 4). The spectrum of the starting material (Fig. 4a) showed the peak at $1334.41 \pm 0.19 \mathrm{~cm}^{-1}$ which is characteristic of diamond phase of carbon considering the shift of $2 \mathrm{~cm}^{-1}$ to smaller wavenumber [17]. This shift was already identified as a compression state of diamond samples [1]. The diamond peak was also observed in the Raman spectra of NDs obtained by ultrasonic cavitation in the absence of $\mathrm{ZrO}_{2}$ beads (Fig. 4b). However, the diamond peak was observed at $1326.80 \pm 4.78 \mathrm{~cm}^{-1}$, which means that there is not shift from characteristic diamond $[43,57]$. The association between NDs size and the shift of Raman peak was clearly showed in the work of Yoshikawa et al. [57] where the diamond peak was shifted by $13 \mathrm{~cm}^{-1}$ to smaller wavenumber in the Raman spectra of NDs with $5 \mathrm{~nm}$ of diameter. In the work of Sun et al. [43] the Raman peak shift in function of NDs size was attributed to the phonon confinement effect. The Raman peak of diamond in the spectra of NDs of $90 \mathrm{~nm}$ and $35 \mathrm{~nm}$ of diameter was identified at $1329 \mathrm{~cm}^{-1}$ and $1325 \mathrm{~cm}^{-1}$, respectively [43].

The wide band observed in both spectra at $1499.00 \pm 2.76 \mathrm{~cm}^{-1}$ and the low-intensity peak at $1500.00 \pm 8.09 \mathrm{~cm}^{-1}$ indicated the presence of graphite phase which is a result of the use of graphite as substrate in the HFCVD reactor for CVD diamond growing.

The diamond was also characterized by X-ray diffractometry. Diffraction patterns of starting material (black line) and ND/0 $\mathrm{h}$ are shown in Fig. 5. XRD pattern for both samples showed a strong diffraction peak at $43.8^{\circ}$, and two other peaks at $75.2^{\circ}$ and $91.4^{\circ}$, characteristic of diamond crystalline plane of (111), (220) and (311).

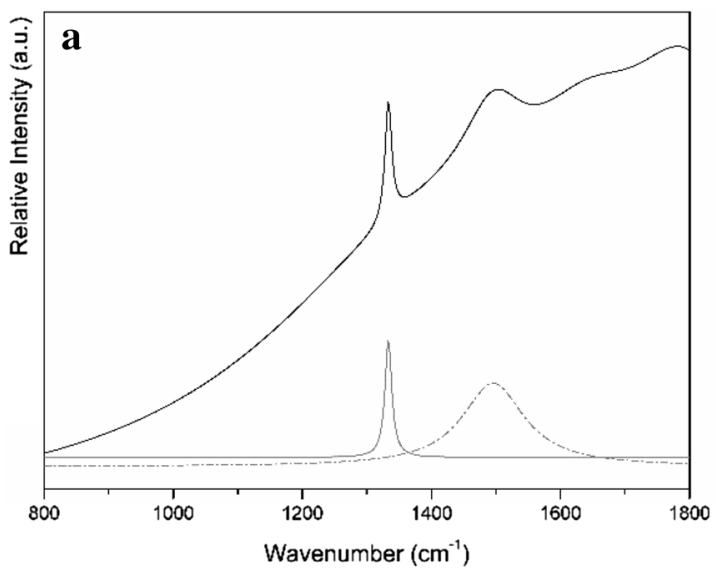

Fig. 4 Raman spectra of diamond samples (excitation with laser at $514 \mathrm{~nm}$ ). a Raw diamond sample. b NDs grains obtained after ultrasonic cavitation process without $\mathrm{ZrO}_{2}$ beads (ND/O h). The spectral

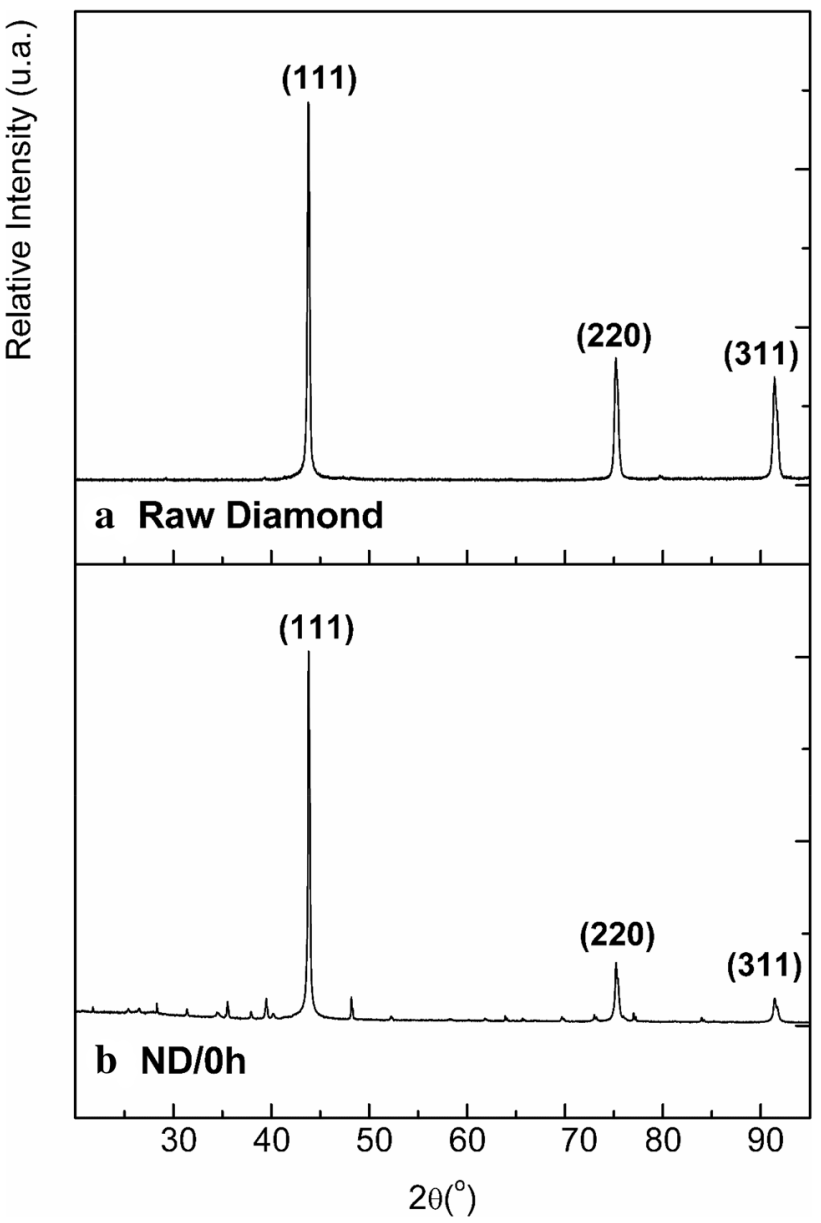

Fig. 5 X-ray diffraction for the samples. a Raw diamond sample. $\mathbf{b}$ NDs grains obtaining after ultrasonic cavitation process without $\mathrm{ZrO}_{2}(\mathrm{ND} / \mathrm{O} \mathrm{h})$

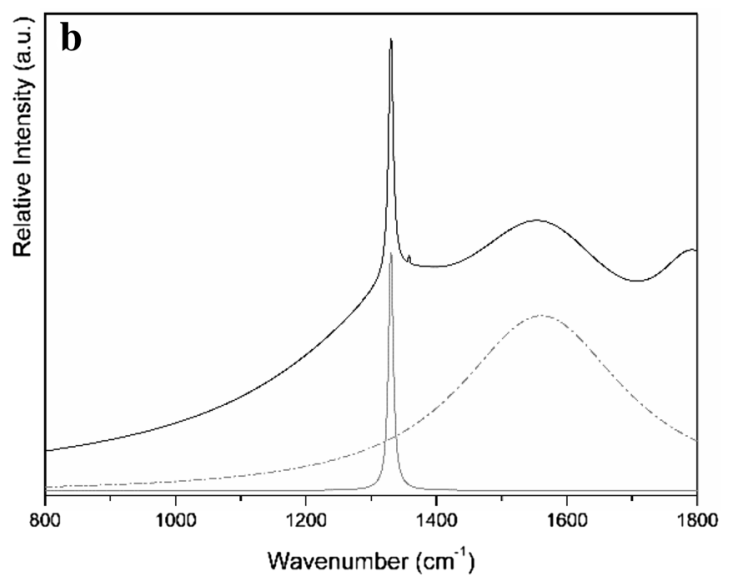

deconvolution of each band are represented by the gray continuous and dashed 


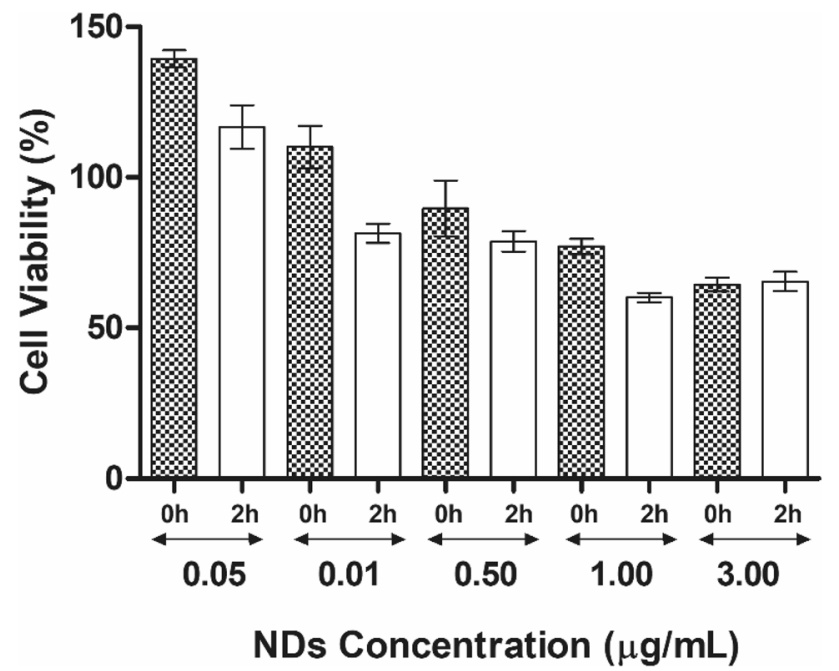

Fig. 6 Cell viability measured by MTT assay for NDs/0 $\mathrm{h}$ and $\mathrm{NDs} / 2 \mathrm{~h}$ after $24 \mathrm{~h}$ of incubation with MEF cells with suspension concentrations of $0.05-3 \mu \mathrm{g} / \mathrm{mL}$. Results are given as mean $\pm S D$ $(n=3)$

\subsection{Cell viability assay}

Cell viability of MEF cells decreased in function of NDs concentration after $24 \mathrm{~h}$ of incubation (Fig. 6). Similar behavior was observed for NDs suspension without centrifugation (ND/0 $h$ ) and after centrifugation (ND/2 h), suggesting the negligible influence of NDs size on the cytotoxicity when the NDs are at the range of $77-22 \mathrm{~nm}$. According to the stablished value of $70 \%$ of cell viability as the minimal value to consider a material as non-cytotoxic (ISO 10-9935) [14], the NDs were only cytotoxic at the concentration of $1 \mu \mathrm{g} / \mathrm{mL}$ after $2 \mathrm{~h}$ of centrifugation. At this concentration, cell viability of MEF cells was of $60 \%$, a value very close to the limit value of $70 \%$. Therefore, the cytotoxicity of these NDs was further investigated by using NDs suspension at higher concentrations (Fig. 7). Surprisingly, cell viability did not decrease lower than $58-60 \%$ and even at higher concentration of $116 \mu \mathrm{g} / \mathrm{mL}$, cell viability was of $70 \%$. The absence of cytotoxicity of NDs at high concentration were also observed by other researchers. Gismondi et al. [11] reported values of cell viability higher than $80 \%$ after incubation of B16-F10 and HeLa cells with NDs of 4-5 nm at $200 \mu \mathrm{g} / \mathrm{mL}$. Similarly, Schrand et al. [40] observed high cell viability of neuroblastoma and macrophage cells incubated with 2-10 nm NDs at concentrations of 5-100 $\mu \mathrm{g} /$ $\mathrm{mL}$.

From our experience and as reported by other authors, nanoparticles size and colloidal state have critical roles in the interaction with cell membrane and consequently to cytotoxicity. In fact, the main parameter is the ratio between lipid bilayer thickness and nanoparticle diameter.

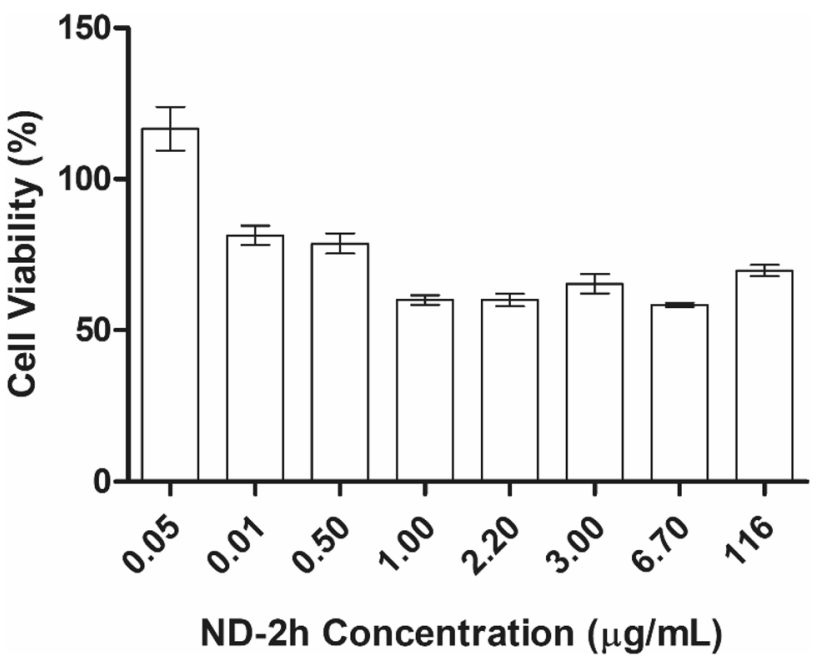

Fig. 7 Cell viability measured by MTT assay for ND/2 $\mathrm{h}$ after $24 \mathrm{~h}$ of incubation with MEF cells with NDs at different concentrations $(0.05-116 \mu \mathrm{g} / \mathrm{mL})$. Its are given as mean $\pm \mathrm{SD}(\mathrm{n}=3)$

Small nanoparticles were able to pierce the cell membrane, being inserted into the membrane or inducing multiple pore formation. In this case, the higher concentration of the nanoparticles in suspension, the higher the cytotoxicity. Nevertheless, bigger nanoparticles ( 100-200 nm) were shown to be covered by the lipid bilayer becoming embedded into the membrane but did not induce pore formation. This information supports our claim that NDs of 22-77 nm were cytotoxic at low concentration because at the range of $0.01-1.00 \mu \mathrm{g} / \mathrm{mL}$ they interact with cell membrane as individual nanoparticles, compromising cell viability due to pore formation in the cell membrane. When the concentration was further increased, NDs aggregated and therefore interacted with the membrane as bigger aggregates, causing less severe cell damage. As already reported by other authors [8,54], NDs aggregation is also promoted by the cell culture medium due to the protein corona that is formed around the NDs surface.

\subsection{NDs surface chemistry}

One of the most important features of NDs is the surface chemistry since it will provide the possibility of surface functionalization in order to promote biological or materials application. The surface chemistry depends on the method used for obtaining NDs. Commonly NDs have oxidized and polyfunctionalized surfaces [22], which hampers the additional and selective chemical modification [18].

The FT-IR spectra of the raw sample and the NDs obtained herein are depicted in Fig. 8. It is known that the absorption of two phonons by bulk diamond results in several bands in the range of $1800-2600 \mathrm{~cm}^{-1}$ [38]. However, no phonons absorption has been detected by FT-IR 


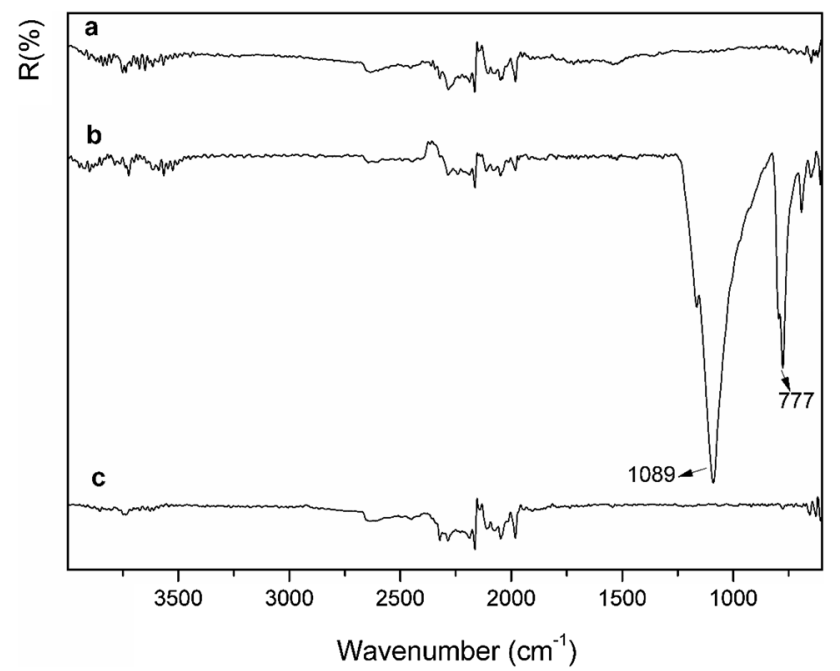

Fig. 8 Infrared spectra a Raw Diamond, b ND/0 h, c ND/0 h after acid treatment for removing $\mathrm{SiO}_{2}$ from the sample

of NDs smaller than $500 \mathrm{~nm}$. Therefore, the low intense bands observed herein in these region were assigned to two phonons absorption of NDs aggregates formed during the freeze-drying process. It is also possible to assign these absorption bands to the incomplete $\mathrm{CO}_{2}$ purging of the spectrometer and hence they would not be related to the NDs as reported by Petit and Puskar [38]. In this way, in order to investigate the surface chemistry, FT-IR spectra were analyzed at the range of $700-1850 \mathrm{~cm}^{-1}$ and $2800-4000 \mathrm{~cm}^{-1}$. The absence of absorption bands in the FT-IR spectrum of raw diamond confirmed that this sample did not contain contaminants. Even if it would be expected that the surface was partially hydrogenated, it would be undetectable by FT-IR due to the low degree of hydrogenation. The FT-IR spectrum of NDs showed a very intense band at $1089 \mathrm{~cm}^{-1}$ and $777 \mathrm{~cm}^{-1}$, which were attributed to $\mathrm{Si}-\mathrm{O}-\mathrm{Si}$ stretching and bending, suggesting the contamination of the sample with silica. This contamination was probably from the agate mortar wherein the raw diamond was macerated at the beginning of the process of NDs preparation.

Despite the contamination with silica, FT-IR spectrum indicated that NDs obtained herein directly from ultrasound cavitation did not showed surface chemical groups which could explain the low cytotoxicity described above for NDs at low concentrations. The contamination with silica could be eliminated by acid treatment with $\mathrm{HF}$ followed by washing with deionized water. The successfulness of cleaning step could be certified by the absence of silica absorption band in the FT-IR spectra of cleaned NDs (Fig. 8c).

Although the process described here had been proved to be worthy to obtain NDs in aqueous suspension, the

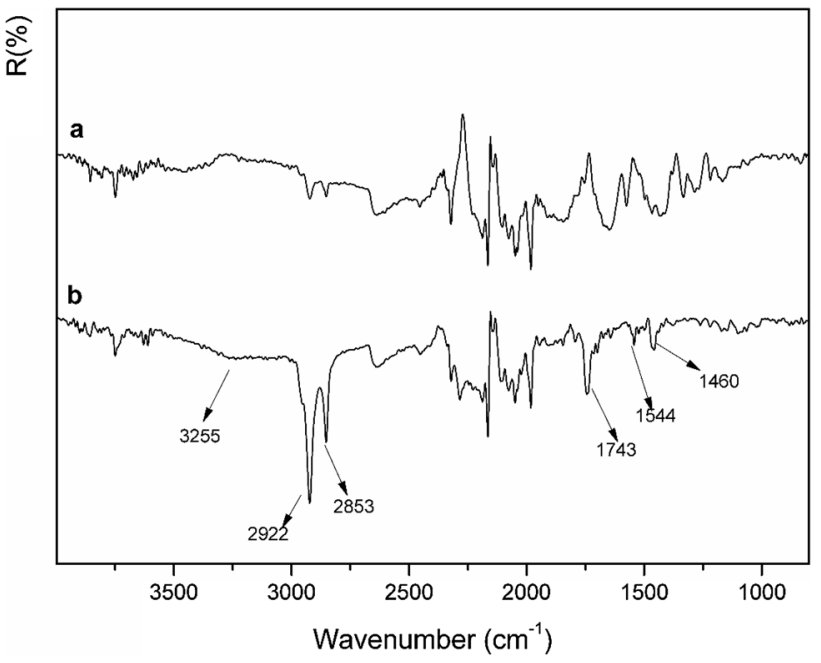

Fig. 9 Schematic representation of the carboxylation process and FT-IR spectra a ND-H, b ND-COOH

lack of chemical functionality could hamper further application of these materials in biomedical or materials field. Controlling the NDs surface chemistry requires a sample of purified NDs with only one type of functional group at the surface.

Therefore, NDs were firstly hydrogenated by PECVD and thereafter carboxilated by chemical photofunctionalization.

The FT-IR spectrum of the NDs subjected to the surface hydrogenation process (ND-H) is shown in Fig. 9a. Hydrogenation was evidenced mainly by the presence of the bands centered at $2853 \mathrm{~cm}^{-1}$ and $2922 \mathrm{~cm}^{-1}$ that were attributed to the symmetric and asymmetric elongation vibrations of $\mathrm{CH}_{2}$ on the surace of NDs $[10,18,44,50]$. In addition to a monofunctionalized surface, the hydrogenation process is known to facilitate the further functionalization with carboxyl groups. The presence of carboxyl groups at NDs surface opens the possibility of NDs coupling with several molecules including biomolecules such as proteins by covalent linking with terminal amine groups $[6,13,33]$.

The absorption band centered at $1743 \mathrm{~cm}^{-1}$ (Fig. 9b) is characteristic of carboxyl groups $[44,50]$ and therefore it was considered an evidence of the successful carboxylation. It was also observed the increased intensity of the absorption bands at $2853 \mathrm{~cm}^{-1}$ and $2922 \mathrm{~cm}^{-1}$ which are characteristic of $\mathrm{C}-\mathrm{H}$ (symmetric and asymmetric elongation vibrations) of alkanes [44]. Since there were no alkane groups at NDs surface before the functionalization, the increased intensity of these bands was attributed to the $\mathrm{CH}_{2}$ from the acrylic acid molecule which could also be responsible for the bands at $1000-1500 \mathrm{~cm}^{-1}$, which correspond to the $\mathrm{CH}$ or $\mathrm{CH}_{2}$ chemical groups [42]. A slightly 
larger band around $3255 \mathrm{~cm}^{-1}$ was attributed to the stretching mode of the $\mathrm{OH}$ bond and the other band at $1560 \mathrm{~cm}^{-1}$ was attributed to the asymmetric vibration of COO- chemical group [18]. Both bands were considered additional indicatives of the successful carboxylation. It is important to point out that there was no carboxyl group directly bound to $C$ from ND surface. Instead, it is expected that the molecule of acrylic acid was bonded after the breakdown of the unsaturated bond in its molecular structure. For this reason, the carboxyl group identified in the FT-IR spectrum was from acrylic acid, as well as the $\mathrm{CH}_{2}$ group. The absorption band of both group showed increased intensity after functionalization with acrylic acid. This increased intensity could not be a result of the presence of unbonded acrylic acid since the excess of acid was washed out after ND functionalization and even it would be still present, the absorption band would not correspond to $\mathrm{CH}$ of alkanes, instead it would correspond to $\mathrm{CH}$ of unsaturated bonds from acrylic acid that did not react with ND surface. Unbonded acrylic acid would also be identified by the absorption band of unsaturated $\mathrm{C}-\mathrm{C}$ bonds, which were absent in the FT-IR of functionalized ND.

The functionalization of NDs surface was also monitored by XPS of carboxylated NDs (Fig. 10). The Fig. 10 shows XPS wide scans and fits of $O(1 s)$ and $C(1 S)$ bands of ND-COOH. XPS analysis of wide scan showed peaks of $\mathrm{C}(1 \mathrm{~s})$ at $285 \mathrm{eV}$ (Fig. 10a) which is in agreement with the known value of binding energy of $C(1 \mathrm{~s})$ from diamond. Therefore, it was an indicative that no changes of diamond occured during the functionalization process. The deconvoluted peak of O(1s) (Fig. 10b) showed 4 values of binding energy: 284.3 and $284.8 \mathrm{eV}$ assigned to $\mathrm{C}-\mathrm{C}, 285.9$ (C-O) and $288.8(\mathrm{COOH})$. The $\mathrm{C}(1 \mathrm{~S})$ peak was deconvoluted to 3 values of binding energy: $533.6(\mathrm{C}-\mathrm{OH}), 532.1(\mathrm{C}=\mathrm{O})$ and 530.8 (Si). These results indicated the high density of carboxyl groups which was in line with the XPS characterization of carboxylated NDs reported by other researchers $[25,50]$. The presence of $\mathrm{Si}$ identified in the wide scan and in the deconvoluted $C(1 \mathrm{~S})$ was assigned to the presence of amorphous $\mathrm{Si}$ that could be remaining contamination of the Si substrate used to grow the raw diamond.

\section{Conclusion}

This work present a very simple method to obtain NDs from CVD diamond leftover with columnar structure. This methodology includes maceration followed by ultrasonic cavitation in water and centrifugation of the final suspension. It was shown that despite a number of research works had pointed the important role of $\mathrm{ZrO}_{2}$ beads in the cavitation process in order to reduce the size of the NDs, herein,
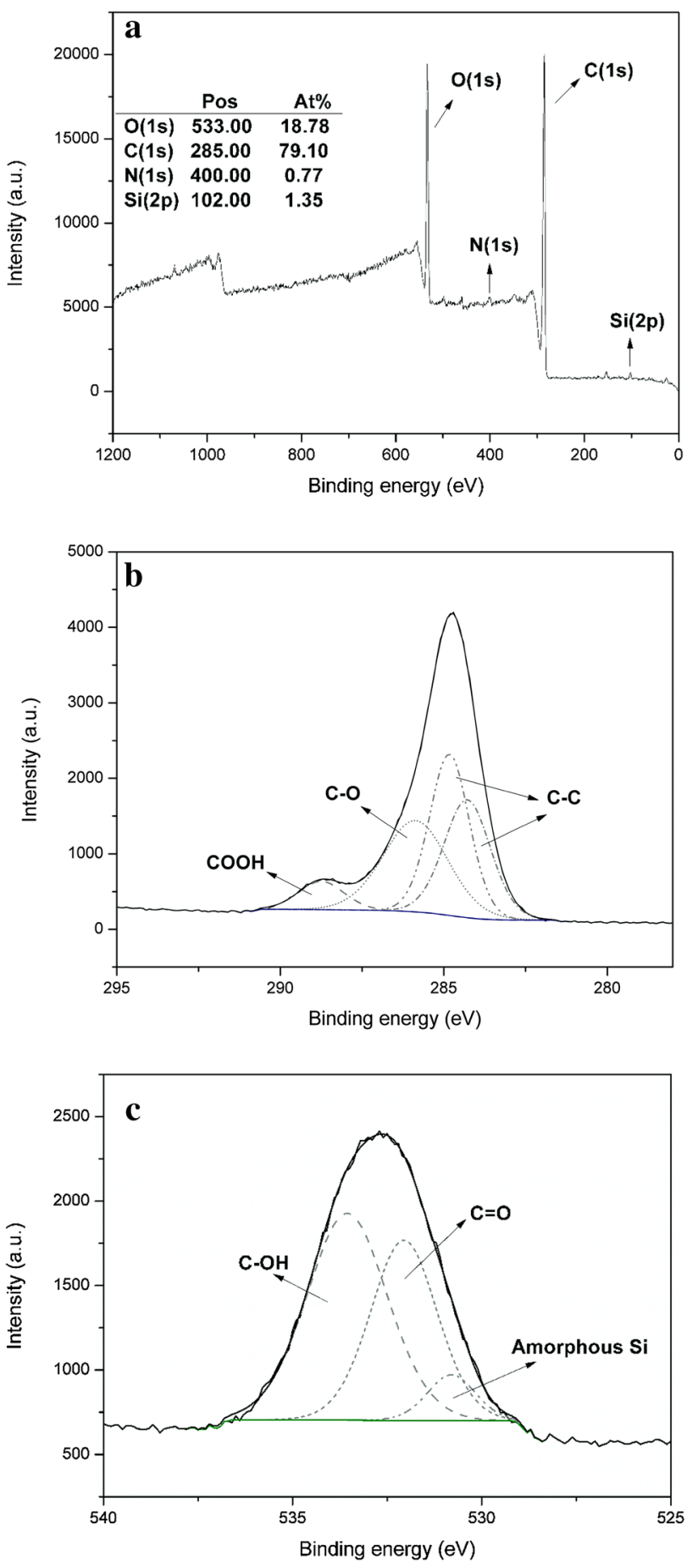

Fig. 10 XPS spectra of ND-COOH a Wide scan. b C(1s) ND-COOH. c $\mathrm{O}(1 \mathrm{~s}) \mathrm{ND}-\mathrm{COOH}$

they had no influence in size. Furthermore, the NDs suspension obtained in the absence of $\mathrm{ZrO}_{2}$ beads presented better dispersion and size homogeneity then the NDs obtained in the presence of $\mathrm{ZrO}_{2}$ beads. Silica was clearly the main impurity of NDs obtained herein. Certainly, this impurity was caused by the maceration step with agate 
mortar even so, it was present at low concentration since it was identified in the FT-IR spectra but not in DRX analysis. Acid treatment proved to be a successful tool to clean off $\mathrm{SiO}_{2}$ from the samples. The in vitro assays performed with MEF cells showed that the NDs obtained by this methodology had limited cytotoxicity at intermediary concentration but were not cytotoxic at low and higher concentration. This is a very positive feature considering that one of the most useful application of NDs has been as drug carriers or diagnostic agents. In conclusion, it was reported here a facile methodology to obtain NDs of low diameter and straight size distribution. Additionally, this methodology provides NDs in aqueous suspension with high colloidal stability and high Zeta-potential. Notably, the main advantage of this methodology is the low cost since the starting material was CVD diamond leftover from reactors. Nevertheless, the low concentration of the final suspension has to be pointed as the main drawback of the process.

Therefore, further investigation is needed in order to scale up this method.

Acknowledgements Institute for Advanced Sea Studies (IEAMar/ UNESP) and Brazilian National Council for Scientific and Technological (CNPq).

Funding The funding was provided by Fundação de Amparo à Pesquisa do Estado de São Paulo (Grant Nos. 2017/01697-6 and 2012/15857-1).

\section{Compliance with ethical standards}

Conflict of interest The authors declare that there is no conflict of interest.

\section{References}

1. Ager JW III, Veirs DK, Rosenblatt GM (1991) Spatially resolved Raman studies of diamond films grown by chemical vapor deposition. Phys Rev B 8:6491-6500. https://doi.org/10.1103/PhysR evB.43.6491

2. Balasubramanian G, Chan IY, Kolesov R, Al-Hmoud M, Tisler J, Shin C, Kim C, Wojcik A, Hemmer PR, Krueger A, Hanke T, Leitenstorfer BR, Jelezko F, Wrachtrup J (2008) Nanoscale imaging magnetometry with diamond spins under ambient conditions. Nature 455:648-651. https://doi.org/10.1038/nature07278

3. Basso L, Gorrini F, Cazzanelli M, Bazzanella N, Bifon A, Miotello A (2018) All-optical single-step process for production of nanometric-sized fluorescent diamonds. Nanoscale 10:5738-5744. https://doi.org/10.1039/c7nr08791h

4. Brouri R, Beveratos A, Poizat JP, Grangier P (2000) Photon antibunching in the fluorescence of individual color centers in Diamond. Opt Lett 25:1294-1296. https://doi.org/10.1364/ OL.25.001294

5. Chan WC, Udugama B, Kadhiresan P, Kim J, Mubareka S, Weiss PS, Parak WJ (2016) Patients, here comes more nanotechnology. ACS Nano 10:8139-8142. https://doi.org/10.1021/acsna no.6b05610
6. Chung PH, Perevedentseva E, Tu JS, Chang CC, Cheng CL (2006) Spectroscopic study of bio-functionalized nanodiamonds. Diam Relat Mater 15:622-625. https://doi.org/10.1016/j.diamo nd.2005.11.019

7. Eidelman E, Siklitsky V, Sharonova L, Yagovkina M, Vul AY, Takahashi M, Inakuma M, Ozawa M, Ōsawa E (2005) A stable suspension of single ultrananocrystalline diamond particles. Diam Relat Mater 14:1765-1769. https://doi.org/10.1016/j.diamo nd.2005.08.057

8. Eldawud R, Reitzig M, Opitz J, Rojansakul Y, Jiang W, Nangia S, Dinu CZ (2016) Combinatorial approaches to evaluate nanodiamond uptake and induced cellular fate. Nanotechnology 27:85107-85118. https://doi.org/10.1088/09574484/27/8/08510 7

9. Galimov EM, Kudin AM, Skrobogatskii VN, Plotnichenko VG, Bondarev OL, Zarubin BG, Strazdovski VV, Aronin AS, Fisenko AV, Bykov IV, Barinov AY (2004) Experimental corroboration of the synthesis of diamond in the cavitatior process. Dokl Phys 49:150-153. https://doi.org/10.1134/1.1710678

10. Girard HA, Arnault JC, Perruchas S, Saada S, Gacoin T, Boilot JP, Bergonzo P (2010) Hydrogenation of nanodiamonds using MPCVD: a new route toward organic functionalization. Diam Relat Mater 19:1117-1123. https://doi.org/10.1016/j.diamo nd.2010.03.019

11. Gismondi A, Rein G, Orlanducci S, Mizzoni F, Gay S, Terranova ML, Canini A (2015) Nanodiamonds coupled with plant bioactive metabolites: a nanotech approach for cancer therapy. Biomaterials 38:22-35. https://doi.org/10.1016/j.biomateria Is.2014.10.057

12. Gorrini F, Cazzanelli M, Bazzanella N, Edla R, Gemmi M, Cappello V, David J, Dorigoni C, Bifone A, Miotello A (2016) On the thermodynamic path enabling a room-temperature, laser-assisted graphite to nanodiamond transformation. Sci Rep 6:35244. https://doi.org/10.1038/srep35244

13. Härtl A, Schmich E, Garrido JA, Hernando J, Catharino SCR, Walter S, Feulner P, Kromka A, Steinmüller D, Stutzmann M (2004) Protein-modified nanocrystalline diamond thin films for biosensor applications. Nat Mater 3:736-742. https://doi.org/10.1038/ nmat1204

14. International Organization For Standardization. ISO $10993-$ 5: Biological Evaluation of Medical Devices-Tests for in vitro cytotoxicity. Genève (2009)

15. Jimenez CM, Knezevic N, Galan-Rubio Y, Szunerits S, Boukherroub R, Teodorescu F, Croissant JG, Hocine O, Seric M, Raehm L, Stojanovic V, Aggad D, Maynadier M, Garcia M, Gary-Bobo M, Durand J (2016) Core-shell nanodiamonds-periodic mesoporous organosilica nanoparticles for two-photon imaging, photodynamic therapy and synergistic $\mathrm{pH}$ responsive drug delivery. J Mater Chem B 4:5803-5808. https://doi.org/10.1039/c6tb0 $1915 \mathrm{C}$

16. Kh KA, Aloyan SG, May PW, Sargsyan R, Khachatryan VA, Baghdasaryan VS (2008) Graphite-to-diamond transformation induced by ultrasound cavitation. Diam Relat Mater 17:931-936. https://doi.org/10.1016/j.diamond.2008.01.112

17. Knight DS, White WB (1989) Characterization of diamond films by Raman spectroscopy. J Mater Res 2:385-393. https://doi. org/10.1557/JMR.1989.0385

18. Korolkov VV, Kulakova II, Tarasevich BN, Lisichkin GV (2007) Dual reaction capacity of hydrogenated nanodiamond. Diam Relat Mater 16:2129-2132. https://doi.org/10.1016/j.diamo nd.2007.07.018

19. Krüger A, Liang Y, Jarre G, Stegk J (2006) Surface functionalisation of detonation diamond suitable for biological applications. J Mater Chem 16:2322-2328. https://doi.org/10.1039/b601325b

20. Krueger A, Ozawa M, Jarre G, Liang Y, Stegk J, Lu L (2007) Deagglomeration and functionalisation of detonation 
diamond. Phys Status Solidi (a) 204:2881-2887. https://doi. org/10.1002/pssa.200776330

21. Krueger A (2008) Diamond nanoparticles: jewels for chemistry and physics. Adv Mater 20:2445-2449. https://doi. org/10.1002/adma.200701856

22. Krueger A, Lang D (2012) Functionality is key: recent progress in the surface modification of nanodiamond. Adv Func Mater 22:890-906. https://doi.org/10.1002/adfm.201102670

23. Le Sage D, Arai K, Glenn DR, DeVience SJ, Pham LM, Rahn-Lee L, Lukin M, Yacoby A, Komelili A, Walsworth R (2013) Optical magnetic imaging of living cells. Nature 496:486-491. https ://doi.org/10.1038/nature12072

24. Liang $Y$, Ozawa M, Krueger A (2009) A general procedure to functionalize agglomerating nanoparticles demonstrated on nanodiamond. ACS Nano 3:2288-2296. https://doi. org/10.1021/nn900339s

25. Lim DG, Kim KH, Kang E, Lim SH, Ricci J, Sung SK, Kwon MT, Jeong SH (2016) Comprehensive evaluation of carboxylated nanodiamond as a topical drug delivery system. Int J Nanomed 11:2381-2395. https://doi.org/10.2147/IJN.S1048 59

26. Lin YC, Perevedentseva E, Tsai LW, Wu KT, Cheng CL (2012) Nanodiamond for intracellular imaging in the microorganisms in Vivo. J Biophoton 5:838-847. https://doi.org/10.1002/jbio.201200088

27. Ma YZ, Zou GT, Yang HB, Meng JF (1994) Conversion of fullerenes to diamond under high temperature. Appl Phys Lett 65:822823. https://doi.org/10.1063/1.112242

28. Maze RJ, Stanwix PL, Hodges JS, Hong S, Taylor JM, Cappellaro P, Jiang L, Dutt MVG, Togan E, Zibrov AS, Yacoby A, Walsworth RL, Lukin MD (2008) Nanoscale magnetic sensing with an individual electronic spin in diamond. Nature 455:644-647. https:// doi.org/10.1038/nature07279

29. Medina O, Nocua J, Mendoza F, Gomez-Moreno R, Avalos J, Rodriguez C, Morell G (2012) Bactericide and bacterial anti-adhesive properties of the nanocrystalline diamond surface. Diam Relat Mater 22:77-81. https://doi.org/10.1016/j.diamond.2011.12.022

30. Mitev DP, Townsend AT, Paull B, Nesterenko PN (2013) Direct sector field ICP-MS determination of metal impurities in detonation nanodiamond. Carbon 60:326-334. https://doi.org/10.1016/j. carbon.2013.04.045

31. Mitev DP, Townsend AT, Paull B, Nesterenko PN (2014) Screening of elemental impurities in commercial detonation nanodiamond using sector field inductively coupled plasma-mass spectrometry. J Mater Sci 49:3573-3591. https://doi.org/10.1007/ s10853-014-8036-3

32. Mochalin VN, Sagar A, Gour S, Gogotsi Y (2009) Manufacturing nanosized fenofibrate by salt sssisted milling. Pharm Res 26:1365-1370. https://doi.org/10.1007/s11095-009-9846-x

33. Mochalin VN, Shenderova O, Ho O, Gogotsi Y (2012) The properties and applications of nanodiamonds. Nat Nanotechnol 7:11-23. https://doi.org/10.1038/nnano.2011.209

34. Ōsawa E (2007) Recent progress and perspectives in singledigit nanodiamond. Diam Relat Mater 16:2018-2022. https:// doi.org/10.1016/j.diamond.2007.08.008

35. Park JW, Kim KS, Hwang NM (2016) Gas phase generation of diamond nanoparticles in the hot filament chemical vapor deposition reactor. Carbon 106:289-294. https://doi.org/10.1016/j. carbon.2016.05.035

36. Pentecost A, Gour S, Mochalin VN, Knoke I, Gogotsi Y (2010) Deaggregation of nanodiamond powders using salt and sugarassisted milling. ACS Appl Mater Interfaces 2:3289-3294. https ://doi.org/10.1021/am100720n

37. Perevedentseva $\mathrm{E}$, Cheng $\mathrm{CY}$, Chung $\mathrm{PH}$, Tu JS, Hsieh YH, Cheng $\mathrm{CL}$ (2007) The interaction of the protein lysozyme with bacteria E-Coli observed using nanodiamond labelling. Nanotechnology 18:1-7. https://doi.org/10.1088/09574484/18/31/315102
38. Petit T, Puskar L (2018) FTIR spectroscopy of nanodiamonds: methods and interpretation. Diam Relat Mater 89:52-66. https ://doi.org/10.1016/j.diamond.2018.08.005

39. Setyawati MI, Mochalin VN, Leong DT (2016) Tuning endothelial permeability with functionalized nanodiamonds. ACS Nano 10:1170-1181. https://doi.org/10.1021/acsnano.5b06487

40. Schrand AM, Huang $\mathrm{H}$, Carlson C, Schlager JJ, Osawa E, Hussain SM, Dai L (2007) Are diamond nanoparticles cytotoxic. J Phys Chem Lett B 111:2-7. https://doi.org/10.1021/jp066387v

41. Shenderova O, Petrov I, Walsh J, Grichko V, Grishko V, TylerT, Cunningham $G$ (2006) Modification of detonation nanodiamonds by heat treatment in air. Diam Relat Mater 15:1799-1803. https:// doi.org/10.1016/j.diamond.2006.08.032

42. Shul G, Actis P, Marcus B, Opallo M, Boukherroub R, Szunerits $S$ (2008) Solvent-free chemical functionalization of hydrogenterminated boron-doped diamond electrodes with diazonium salts in ionic liquids. Diam Relat Mater 17:1394-1398. https:// doi.org/10.1016/j.diamond.2007.12.007

43. Sun KW, Wang JY, Ko TY (2008) Photoluminescence and Raman spectroscopy of single diamond nanoparticle. J Nanoparticle Rea 10:115-120. https://doi.org/10.1007/s11051-008-9406-z

44. Szunerits S, Boukherroub R (2008) Different strategies for functionalization of diamond surfaces. J Solid State Electrochem 12:1205-1218. https://doi.org/10.1007/s10008-007-0473-3

45. Toh TB, Lee DK, Hou W, Abdullah LN, Nguyen J, Ho D, Chow EKH (2014) Nanodiamond-mitoxantrone complexes enhance drug retention in chemoresistant breast cancer cells. Mol Pharm 118:2683-2691. https://doi.org/10.1021/mp5001108

46. Turcheniuk K, Trecazzi C, Deeleepojananan C, Mochalin VN (2016) Salt-assisted ultrasonic deaggregation of nanodiamond. ACS Appl Mater Interfaces 8:25461-25468. https://doi. org/10.1021/acsami.6b08311

47. Turcheniuk K, Mochalin VN (2017) Biomedical applications of nanodiamond (Review). Nanotechnology 28:252001. https:// doi.org/10.1088/1361-6528/aa6ae4

48. Vandenbulcke L, Gries T, Rouzaud JN (2009) Nanodiamonds in dusty low-pressure plasmas. Appl Phys Lett 94:044106. https:// doi.org/10.1063/1.3075604

49. Volkov DS, Proskurnin MA, Korobov MV (2014) Elemental analysis of nanodiamonds by inductively-coupled plasma atomic emission spectroscopy. Carbon 74:1-13. https://doi. org/10.1016/j.carbon.2014.02.072

50. Wang C, Huang N, Zhuang H, Yang B, Zhai Z, Jiang X (2016) Photochemical functionalization of diamond films using a shortcarbon chain acid. Chem Phys Lett 646:87-90. https://doi. org/10.1016/j.cplett.2016.01.024

51. Wehling J, Dringen R, Zare RN, Maas M, Rezwan K (2014) Bactericidal activity of partially oxidized nanodiamonds. ACS Nano 8:6475-6483. https://doi.org/10.1021/nn502230m

52. Welz S, Gogotsi Y, MacNallan MJ (2003) Nucleation, growth and graphitization of diamond nanocrystals during chlorination of carbides. J Appl Phys 93:4207-4214. https://doi. org/10.1063/1.1558227

53. Williams OA, Hees J, Dieker C, Jäger W, Kirste L, Nebel CE (2010) Size-dependent reactivity of diamond nanoparticles. ACS Nano 4:4824-4830. https://doi.org/10.1021/nn100748k

54. Woodhams B, Ansel-Bollepalli L, Surmacki J, Knowles H, Maggini L, de Volder M, Atatüre M, Bohndiek S (2018) Graphitic and oxidised high pressure high temperature (HPHT) nanodiamonds induce differential biological responses in breast cancer cell lines. Nanoscale 10:12169-12179. https://doi.org/10.1039/c8nr0 2177e

55. Xing Y, Dai LM (2009) Nanodiamonds for Nanomedicine. Nanomedicine 4:207-218. https://doi.org/10.2217/17435889.4.2.207

56. Yang GW, Wang JB, Liu QX (1998) Preparation of nanocrystalline diamonds using pulsed laser induced reactive 
quenching. J Phys: Condens Matter 10:7923-7930. https://doi. org/10.1088/0953-8984/10/35/024

57. Yoshikawa M, Mori Y, Maegawa M, Katagiri G, Ishida H, Ishitani A (1993) Raman scattering from diamond particles. Appl Phys Lett 62:3114-3116. https://doi.org/10.1063/1.109154

58. Zhao J, Lai H, Lu H, Barner-Kowollik C, Stenzel MH, Xiao P (2016) Fructose-coated nanodiamonds: promising platforms for treatment of human breast cancer. Biomacromol 17:2946-2955. https://doi.org/10.1021/acs.biomac.6b00754

59. Zhu Y, Li J, Li W, Zhang Y, Yang X, Chen N, Sun Y, Zhao Y, Fan C, Huang Q (2012) The biocompatibility of nanodiamonds and their application in drug delivery systems. Theranostics 2:302312. https://doi.org/10.7150/thno.3627

Publisher's Note Springer Nature remains neutral with regard to jurisdictional claims in published maps and institutional affiliations. 